\title{
Surdos e ouvintes: por uma educação intercultural, democrática e plural
}

\author{
Deaf and Hearing: towards Intercultural, Democratic and Plural Education
}

Sordos y oyentes: hacia la educación intercultural, democrática y plural

\author{
Valkiria de Novais Santiago \\ Professora doutoranda na Universidade Estadual do Paraná, União da Vitória, Paraná, Brasil. \\ kiriansantiago@yahoo.com.br \\ ORCID - https://orcid.org/0000-0002-4806-851X
}

Maria Ivete Basniak

Professora doutora na Universidade Estadual do Paraná, União da Vitória, Paraná, Brasil. basniak2000@yahoo.com.br

ORCID - http://orcid.org/0000-0001-5172-981X

Sani de Carvalho Rutz da Silva

Professora doutora na Fundação Universidade Tecnológica Federal do Paraná, Ponta Grossa, Paraná, Brasil.

sani@utfpr.edu.br

ORCID - http://orcid.org/0000-0002-1548-5739

\section{Antônio Charles Santiago de Almeida}

Professor Doutor na Universidade Estadual do Paraná, União da Vitória, Paraná, Brasil. sandiabo@yahoo.com.br

ORCID - https://orcid.org/0000-0002-4988-3153

Recebido em 24 de junho de 2019

Aprovado em 13 de setembro de 2019

Publicado em 12 de novembro de 2019

\section{RESUMO}

O cenário educacional brasileiro configura-se, na contemporaneidade, como espaço heterogêneo, multilíngue e multicultural. Nestes termos, a educação das pessoas surdas apresenta-se como provocação para pesquisadores, surdos e suas famílias, uma vez que, mesmo com avanços nas áreas do ensino e da aprendizagem, o universo do surdo não é contemplado, por diversos motivos, na sua integralidade. Deste modo, o trabalho de pesquisa aqui proposto definiu, como objetivo, analisar e refletir acerca da Educação que vem sendo disponibilizada às pessoas surdas, como forma de propiciar um debate sobre as metodologias e os artefatos culturais que estão sendo utilizados para que as pessoas surdas tenham, no contexto brasileiro, garantido seu direito a uma Educação democrática e plural. A metodologia empregada para esta pesquisa foi de cunho qualitativo, bibliográfica e busca, por meio da análise, compreender se os artefatos culturais cumprem com seu papel, isto é, garantem uma Educação plural e democrática. Por artefatos culturais compreendem-se expressões políticas, linguísticas, artísticas e literárias da comunidade surda. Nesta perspectiva, a hipótese aqui sustentada é de que 
http://dx.doi.org/10.5902/1984686X38705

somente por meio de uma Educação intercultural, conectada com os artefatos da cultura surda, será possível assegurar uma Educação democrática e plural.

Palavras-chave: Surdez; Cultura; Diversidade.

\section{ABSTRACT}

Brazilian educational scenery is configured, in the present days, as a heterogeneous, multilingual and multicultural space. Then, education of deaf people is presented as defiance for researchers, deaf people and their families, once because even with advances in teaching and learning area, the universe of deaf is not contemplated integrally by several reasons. Therefore, the research work here proposed defined as aim at analyze and reflect on the education available for deaf people as a way to provide a debate about the methodologies and cultural artifacts which has been used for deaf people have, in the Brazilian context, ensured their right to a democratic and plural education. The methodology used in this research was in the qualitative and bibliographic approach, and search, through the analysis, understand whether the artifacts play appropriately their role, in other words, if they ensure a plural and democratic education. As cultural artifacts we understand political, linguistic, artistic and literary expressions of deaf community. In this perspective, the hypothesis here suggested is that only by an intercultural education, connected with cultural artifacts of deaf culture will be possible ensure a democratic and plural education.

Keywords: Deafness; Culture; Diversity.

\section{RESUMEN}

El escenario educativo brasileño se configura, en la contemporaneidad, como espacio heterogéneo, multilingüe y multicultural. En estos términos, la educación de las personas sordas se presenta como provocación para investigadores, sordos y sus familias, ya que, aun con avances en las áreas de la enseñanza y el aprendizaje, el universo del sordo no es contemplado, por diversos motivos, exhaustividad. De este modo, el trabajo de investigación aquí propuesto definió, como objetivo, analizar y reflexionar acerca de la Educación que viene siendo puesta a disposición de las personas sordas, como forma de propiciar un debate sobre las metodologías y los artefactos culturales que están siendo utilizados para que las personas sordas tengan, en el contexto brasileño, garantizado su derecho a una Educación democrática y plural. La metodología empleada para esta investigación fue de cuño cualitativo, bibliográfico y búsqueda, por medio del análisis, de comprender si los artefactos culturales cumplen con su papel, es decir, garantizan una Educación plural y democrática. Por artefactos culturales se entienden expresiones políticas, lingüísticas, artísticas y literarias de la comunidad sorda. En esta perspectiva, la hipótesis aquí sostenida es que sólo por medio de una Educación intercultural, conectada con los artefactos de la cultura sorda, será posible asegurar una Educación democrática y plural.

Palabras clave: Sordera; Cultura; Diversidad.

\section{Introdução}

Os espaços educacionais brasileiros constituíram-se, historicamente, como ambientes de conflitos, transformações, aprendizados e de mudanças políticas. Todavia, destaca-se que, com relação à surdez e à educação das pessoas surdas, esses lugares 
foram vistos, durante muito tempo e em certa medida ainda são, como lugares de exclusão, silenciamento e normalização ${ }^{1}$ linguística, cultural, histórica e educacional. Esta constatação, em grande medida, deve-se ao fato de que, no Brasil, no campo ${ }^{2}$ educacional, os agentes que representam a surdez eram invizibilizados; mais do que isto, eram inexistentes e, por isto, os surdos não eram partícipes da agenda educacional e política. No momento presente, tem-se um artefato que é significativo, a política, e que vem demarcando um lugar na disputa do campo da agenda política. Nas palavras de Santana, essa visão

[...] sempre existiu e, antigamente, o preconceito era muito mais forte. As pessoas surdas sempre foram estigmatizadas, consideradas de menor valor social. Afinal, faltavam-lhes a característica eminentemente humana: a linguagem (oral, bem entendido) e suas "virtudes" cognitivas. Sendo destituídos dessas virtudes os surdos eram considerados "humanamente inferiores" (SANTANA, 2007, p. 31, grifos do autor).

A assertiva acima coaduna com a discussão apresentada, isto é, historicamente não havia, no campo da política, uma tensão em torno da temática educação de surdos e, no momento presente, já existem movimentos ${ }^{3}$ organizados que pautam a questão. Noutros termos, tem espaço na agenda política e educacional, pequeno, mas é existente a discussão em torno da pessoa surda no país. Seguindo este raciocínio, a pesquisa proposta elencou, como objetivo, analisar e compreender a educação disponibilizada às pessoas surdas, como forma de permitir um debate acerca das metodologias e artefatos culturais que estão sendo utilizados para assegurar uma educação democrática e plural.

O texto foi estruturado em três momentos: no primeiro tecemos algumas considerações acerca da educação às pessoas surdas, bem como do processo de exclusão linguística e cultural desta minoria ao longo do tempo. No segundo, delineamos o conceito de cultura surda e dos seus artefatos culturais, principalmente no que se refere à Libras e à Literatura Surda. No terceiro e último momento discorremos a respeito da interculturalidade como possibilidade de uma educação mais democrática e plural entre surdos e ouvintes, que apontam aspectos que sustentam nossas conclusões e considerações finais.

\section{Desenvolvimento}

As pessoas surdas, ao longo da história, foram excluídas, segregadas e consideradas incompletas e incapazes de aprender e/ou participar como sujeitos de direitos nos mais diversos ambientes sociais. Corroborando este entendimento, Santos e 
http://dx.doi.org/10.5902/1984686X38705

Goes afirmam que "os surdos, ao longo da história, foram colocados à margem da sociedade, em muitos âmbitos, seja econômico, social, cultural, educacional e político, sendo considerados como incapazes" (2016, p. 21). Frente às argumentações apresentadas por Santos e Goes (2016), observamos que esse processo de exclusão das pessoas surdas começou na antiguidade, mas ainda hoje podemos identificar, em diferentes contextos, a exclusão social, educacional e cultural destas pessoas.

$\mathrm{Na}$ era primitiva, pela falta de organização social e do nomadismo em que as pessoas viviam, os indivíduos que apresentavam alguma relação de dependência e inaptidão social eram eliminados ou abandonados à própria sorte. Segundo Mainieri (2011), a habilidade de ouvir correspondia a um mecanismo de defesa importantíssimo para a sobrevivência naquele período, haja vista que, sem a audição, era impossível ouvir os sons dos animais que ofereciam algum tipo de perigo e, assim, os surdos eram considerados inaptos a sobreviver.

$\mathrm{Na}$ Grécia, especialmente Esparta, por se tratar de uma civilização que valorizava de forma exacerbada a imagem do homem, ou seja, reverenciava a perfeição física e prestava culto ao corpo, as pessoas que nasciam com algum tipo de deformidade física, inabilidade intelectiva, sensorial ou social eram consideradas inaptas a conviver socialmente, pois estavam fora dos padrões estéticos exigidos por esta cultura clássica. Nas palavras de Streiechen

por muito tempo, os surdos foram considerados seres incapazes e incompetentes. Acreditava-se que o pensamento não podia se desenvolver sem a linguagem e que a fala não se desenvolvia sem a audição, portanto, quem não ouvia também não falava e não pensava (STREIECHEN, 2013, p. 19).

Nesta perspectiva apresentada, ainda de acordo com Streiechen (2013), as crianças que nasciam surdas eram consideradas como insensatas, inábeis e destituídas de direitos, haja vista que, neste entendimento, era impossível de se desenvolverem linguística, social e intelectualmente.

Em Roma, no entendimento Strobel (2009), a surdez era uma espécie de castigo ou enfeitiçamento dos deuses. Por isso, os surdos eram punidos com afogamento. Após o seu nascimento, as crianças surdas eram abandonadas pelos familiares, isto é, por sua condição biológica, eram eliminadas, mas os que conseguiam sobreviver eram explorados como escravos ou serviam de gozação para os ricos da época. Neste sentido, 
http://dx.doi.org/10.5902/1984686X38705

em Roma não perdoavam os surdos porque achavam que eram pessoas castigadas ou enfeitiçadas, a questão era resolvida por abandono ou com a eliminação física - jogavam os surdos em rio Tiger. Só se salvavam aqueles que do rio conseguiam sobreviver ou aqueles cujos pais os escondiam, mas era muito raro - e também faziam os surdos de escravos obrigando-os a passar toda a vida dentro do moinho de trigo empurrando a manivela (STROBEL, 2009, p. 17).

Decerto que as culturas clássicas, aqui pensadas como a grega e a romana ${ }^{4}$, quase sempre tomavam o corpo e suas habilidades com certo grau de estética, ou seja, beleza e perfeição. Por isto, sinais de imperfeição, conceito utilizado por estas culturas para as deformidades físicas, apartavam o indivíduo da vida social, seja com a morte ou com a reclusão e o trabalho forçado. Com o tempo, as relações sociais e políticas, bem como o entendimento da cultura modificaram-se e, com isto, as manifestações careceram de maiores e melhores explicações. Isto porque a estética não poderia, com seu ideal de belo, aqui tomado no sentido do corpo, pensado como perfeito, fundamentar e definir as relações da vida social.

Para Weber, ao tratar da ciência, afirma que, "com efeito, não é, de modo algum, evidente que um fenômeno sujeito à lei do progresso albergue sentido e razão" (1968, p. 29). Neste entendimento, a história não pode embarcar no espírito do positivismo e esmerar progresso, pois, segundo o entendimento weberiano, a história não é uma sucessão de fatos ordenados: pelo contrário, configura-se como um amontoado de fatos desordenados que ganham sentido a partir do homem, sujeito da pesquisa, o cientista. Deste modo, após a Idade antiga, bem como a ldade Média, tem-se o advento da idade Moderna e, retomando a assertiva weberiana, não significa que houve ou que há progresso, mais do que isto: quando se opera com ciência não se busca, na linha histórica, progresso no sentido de interpretação e compreensão do fenômeno que evolui, que melhora. Deste modo não se pode, na perspectiva weberiana, pensar a humanidade à luz do progresso, da evolução. Todavia, ainda de acordo com Weber, na continuação da assertiva, "por que motivo, então, nos entregamos a uma tarefa que jamais encontra fim e não pode encontrá-lo?" (1968, p. 29). Para Weber, o papel da ciência é, no seu tempo presente, responder sobre o objeto, mais do que isso, ofertar uma compreensão desinteressada do progresso histórico, mas conectada com o sentido histórico, isto é, com a realidade que se desenrola em um determinado tempo, apresenta-se como perspectiva interpretativa para o sujeito, que deve compreender e interpretar o seu objeto, o mundo circundante. Por isto afirma Weber, "a ciência é, atualmente, uma 'vocação' alicerçada na 
http://dx.doi.org/10.5902/1984686X38705

especialização e posta a serviço de uma tomada de consciência de nós mesmos e do conhecimento das relações objetivas" (1968, p. 47).

Não se pode negar que, na sociedade moderna, a forma de observar determinados fenômenos sociais, sobretudo o da surdez, é ressignificada: as pessoas surdas começam a ser vistas sob outro prisma, começam a surgir os primeiros relatos de trabalhos acerca da educação de pessoas surdas, bem como de trabalhos desenvolvidos na área da educação de crianças surdas como forma de integrá-las na sociedade. Para Oliveira (2011), existem registros de que John Beverley é considerado o primeiro educador de pessoas surdas, porque ele foi o primeiro a conseguir ensinar uma pessoa surda a falar. Retomando a posição weberiana já mencionada, a ciência, no mundo desencantado, com o advento da modernidade, não se limitou a olhar o objeto, mas, na sua condição de especialista, servindo-se de conscientização para o homem, sobretudo das condições objetivas, enalteceu as formas de apreensão do fenômeno, a vida social, não como progresso, o progresso do fenômeno, tampouco como uma teleologia, mas sempre, segundo Weber (1968), com novos olhares, sempre atentos e arregalados para, no tempo presente, interpretar e compreendê-lo.

No fim do Período Moderno e início da Contemporaneidade já existiam dois grupos de pesquisadores que disputavam acerca do melhor método científico para educar as pessoas surdas, um grupo defendia o oralismo e o outro o gestualismo. O oralismo, como método científico, que teve como maior influente Samuel Heinicke, sustentava a ideia de que as pessoas surdas deveriam aprender a falar e, por isto, era preciso ensiná-las para esse fim. Já o segundo método científico, o gestualismo, que contou com o abade L’Epée, seu maior expoente, defendia que a educação dos surdos deveria ser por meio da língua de sinais. Oliveira, ao refletir sobre os métodos científicos do final da Idade Moderna, pontua que

[...] o final da Idade Moderna foi marcado por uma disputa entre o método moderno adotado pelo Abade L'Epée, que utilizava a língua de sinais na educação de surdos (método francês), e o método hoje conhecido como oralista (método alemão), concebido pelo pedagogo alemão Samuel Heinicke (1729-1790), que ensinou vários surdos a falar (OLIVEIRA, 2011, p. 43).

Neste entendimento, compreende-se que, mesmo diante dos avanços no campo da ciência, da educação e do esforço da sociedade para entender e aceitar as diferenças entre surdos e ouvintes, é inegável que, naquele momento da história, muitos ouvintes ainda viam os surdos como deficientes, incapazes. Em outras palavras, ainda existiam 
http://dx.doi.org/10.5902/1984686X38705

alguns vestígios da concepção de que a surdez era uma doença e que, para os surdos se tornarem cidadãos, eles precisavam ser oralizados, precisavam aprender a falar.

Ao final da idade moderna e início Idade Contemporânea, principalmente no final do século XVIII, representou um período áureo na compreensão e defesa da educação dos surdos, uma vez que o abade L'Epée, francês, nascido em 1712, maior expoente do método gestualista, lutou para que os surdos fossem aceitos e reconhecidos como pessoas que falavam uma língua diferente das pessoas ouvintes. É possível apontar, segundo Oliveira (2011), diversas contribuições deste estudioso para a educação dos surdos, das quais se destacam a criação do Instituto nacional de Surdos-mudos em Paris, e ter defendido e sistematizado a língua de sinais como língua natural dos surdos. Ainda, fez a defesa e fortaleceu o movimento do surdo como pessoa humana e agente de direitos.

Decerto que, semelhante a Weber (1968), não se pode conceber a história como caminho de progresso, destoando, assim, do positivismo comtiano. É possível, com o desenvolvimento do discurso científico, bem como da sistematização da ciência, operada, ainda segundo Weber (1968), pelo desencantamento do mundo, apontar avanços nas formas de conceber o surdo e seu universo educacional, cultural, social e político. Todavia, mesmo com os avanços já apresentados, não podemos deixar de afirmar que ainda existe um longo caminho para percorrer e assegurar, na integralidade, uma Educação democrática e cidadã para as comunidades surdas.

No contexto contemporâneo, sobretudo no ambiente brasileiro, visualiza-se certo número de surdos que não estão sequer integrados, pois, para muito deles, a escola de ouvintes é um lugar sem sentido ${ }^{5}$, ou seja, nesta perspectiva, é melhor estar fora do que dentro da escola e universidade. É visível também que, mesmo com essa impressão por parte de alguns surdos, existem comunidades que estão integradas, ou seja, são matriculadas nas escolas, efetivadas como iguais frente aos ouvintes e, desta igualdade resulta o não reconhecimento de suas especificidades. São, nessa conjuntura, os alunos surdos, o que Bourdieu (2014) denominou de os excluídos do interior ${ }^{6}$. Decerto que o conceito bourdieusiano não fora empregado para a comunidade surda, mas que pode, tratando-se de um conceito sociológico, ser utilizado para dar conta da realidade aqui definida, uma vez que, por estarem excluídos no interior, são justamente os que estão integrados, mas que permanecerão nesta condição, condenados a uma falsa democratização do saber. Nas palavras de Bourdieu, "e fazem com que o sistema de 
http://dx.doi.org/10.5902/1984686X38705

ensino, amplamente aberto a todos, e, no entanto, estritamente reservados a alguns, consiga a façanha de reunir as aparências da democratização [...]" (2014, p. 250). Por isto a importância de refletir sobre a escola; mais do que isto, a cultura escolar e sua relação com a diversidade das culturas.

$\mathrm{Na}$ esteira da discussão de conceitos em Bourdieu faz-se premente, especialmente segundo Lulkin (2005), tratar da relação de conceitos, a saber, inclusão/integração, mais do que isso, imbricá-los, pois, para muitas pessoas, o fato de colocar o surdo na escola, integração, já se efetiva a inclusão. É preciso mais do que o direito à escola: deve ser garantido, para além dessa integração, o direito à escola, a inclusão, horizontalização das culturas sem qualquer procedimento de hierarquia e de valoração. Por isto, de acordo com Lulkin "para que haja uma aproximação entre surdos e ouvintes é preciso reconhecer a distância existente tanto entre os corpos como em relação as suas modalidades linguísticas" (2005, p. 41). Neste sentido, é preciso que, com a imbricação dos conceitos de integração/inclusão, mais exatamente com a fusão deles, será possível não só reconhecer o direito da pessoa surda, mas, para além disso, a democratização de sua cultura à luz dessa relação horizontal das culturas. Na continuidade da assertiva, Lulkin acrescenta que

Os estudantes surdos usam, preferencialmente, a língua de sinais, envolvendo o corpo todo, no ato da comunicação. A comunicação visogestual, não cotidiana para os ouvintes, produz formas de apreensão, interpretação e narração do mundo a partir de uma cultura visual. Os educadores e demais profissionais envolvidos no espaço escolar, na melhor das hipóteses, são "estrangeiros" que se aproximam da língua de sinais e da cultura visual, mas privilegiam, pelo hábito e pela própria cultura, a modalidade, a fala, como ato cotidiano de comunicação (LULKIN, 2005, p. 41).

Conforme exposto anteriormente, os avanços na forma de compreender os problemas que entornam a vida do surdo, sobretudo a visão que se tem para com estes sujeitos, ainda é excludente e desigual, pois as práticas escolares continuam alicerçadas, mesmo que de maneira quase imperceptível, nos discursos dominantes de que as pessoas surdas são limitadas, e sem língua e sem cultura próprias. Para Santos, ao tratar desse universo de exclusão e de desigualdades no ambiente escolar,

[...] a escola, ao transmitir os modelos sociais vigentes, reproduz o esquema de dominação, uma vez que é detentora de um saber a que, ainda que em regime democrático, poucos têm acesso. É importante frisar que ter acesso não significa apenas ter matrícula e um lugar físico assegurado, mas ser sujeito participante, tanto social como cognitivamente, da construção e da divisão deste saber (SANTOS, 2012, p. 95). 
http://dx.doi.org/10.5902/1984686X38705

Frente à constatação aqui mencionada, especialmente no que diz respeito à compreensão do sujeito surdo e de como se constitui o seu ambiente escolar, faz-se premente refletir sobre a formação educacional deste sujeito, o outro. Sabemos que esse outro corresponde a todos os agentes que fazem parte de uma cultura e de uma língua que nem sempre correspondem aos padrões da maioria dominante, mas que, de um modo quase geral, não existe, por parte da escola e de forma dominante, na reprodução das estruturas sociais, uma preocupação com esse outro. Dorziat (2009), ao refletir sobre a relação de dominação que existe na escola, entre as culturas, bem como sobre esse outro, pontua que

as dificuldades de aceitar o outro como é, fazem com que o torne igual a mim, atribuindo a ele apenas uma limitação, um desvio. Essa é uma face comum da negação da diferença, da incapacidade de enxergar o outro para além de si mesmo, entendendo que é ilusória a visão de que as pessoas "portam" uma característica desviante, mas que esta característica, como outras, constitui-a como pessoa humana, fazendo-a ser como ela é (DORZIAT, 2009, p,70).

Decerto que surdos e ouvintes pertencem a culturas distintas e que precisam ser reconhecidas, respeitadas e, acima de tudo, valorizadas nos espaços educacionais, nas suas diferenças, até mesmo porque estes ambientes são heterogêneos e plurais, sendo, assim, inapropriada uma visão única acerca da língua, do conhecimento, do sujeito, da cultura e do processo de ensino e de aprendizagem. Diante dessas demandas, a escola precisa reconhecer as especificidades linguísticas, históricas e culturais dos sujeitos que compõem estes espaços, pois só por meio dessa tomada de consciência e de uma mudança atitudinal a respeito dessas especificidades é que se pode assegurar, a todos os envolvidos, no processo de formação e produção do conhecimento, uma educação democrática.

Entretanto, como há uma enorme variedade de perspectivas teóricas e conceituais em torno do que se entende por cultura, isto é, existem diversos autores que discutem a respeito deste conceito, em que parece não haver consenso sobre essa temática, faremos algumas inferências acerca do conceito de cultura no contexto mais genérico, para facilitar a compreensão do proposto nesta pesquisa.

Por ser um tema amplo e complexo, elencamos como base teórica Laraia (2009), que esclarece que a matriz do conceito de cultura, hoje, foi constituída a partir do determinismo biológico e do determinismo geográfico. Para o autor, no determinismo biológico, a cultura é algo que já está impregnado na matriz de determinadas raças; ou 
http://dx.doi.org/10.5902/1984686X38705

seja, existem raças que já nascem predestinadas a serem inferiores e, outras, à condição de superiores. No que compreende o determinismo geográfico, fica claro, nas palavras do autor, que elementos climáticos e geográficos são determinantes no processo de definição da cultura dos grupos e nações. Contrapondo estas duas perspectivas e corroborando com o conceito de cultura defendido nesse trabalho, Laraia (2009), baseado na ideia de cultura acastelada por Kroeber, apresenta-o como fabricação humana. Nesta perspectiva, o ser humano desprende-se da condição de natureza e passa a construir sua própria cultura por meio das relações, das trocas, das interações entre os indivíduos e grupos, no sentido de sobrevivência e felicidade. Nesse sentido, afirma Kroeber, com relação ao homem na sua fabricação cultural, que "ele muda o seu ambiente e pode assim conservar inalterado o seu corpo original. Constrói uma casa fechada, que o protege contra o vento e lhe permite conservar o calor do corpo" (apud Laraia, 2009, p. 41).

Partindo deste ponto, compreendemos que há uma relação entre cultura, interculturalidade e a educação de surdos e ouvintes, uma vez que eles se conectam e se completam na proporção em que ocorre o entrelaçamento de saberes, por meio da infusão de perspectivas culturais entre surdos e ouvintes e, por conseguinte, uma educação democrática e plural, tanto para surdos como para ouvintes. Com isto, na seção seguinte, discutimos a cultura surda.

\section{Cultura Surda: um delineamento mister}

Ao defendermos a cultura como fabricação, abarcamos que ela se constitui a partir do processo de interação e trocas do homem com seus pares e com os mais variados grupos que compõem os espaços escolares e sociais, isto porque essas trocas contribuem para o processo de constituição de si mesmo e do outro/os outros. Nas palavras de Candau, "os 'outros', os diferentes, muitas vezes estão perto de nós, e mesmo dentro de nós, mas não estamos acostumados a vê-los, ouvi-los, reconhecê-los, valorizá-los e interagir com eles" (2013, p. 31, grifos do autor). No contexto de respeito e de valorização do outro, faremos algumas incursões acerca da cultura surda e da contribuição dessa cultura para uma formação cidadã entre surdos e ouvintes.

Ao enfatizarmos a cultura surda, não é nossa intenção desconsiderar a cultura ouvinte, mas apresentar algumas características que, por serem próprias da cultura surda, ainda são pouco divulgadas, conhecidas e valorizadas social e educacionalmente. Entre 
http://dx.doi.org/10.5902/1984686X38705

as características, podemos destacar as experiências visuais e a língua de sinais. Strobel discute que, "se a língua transborda de uma cultura, é um elemento de organizar uma realidade de um grupo que discursa a mesma língua como elemento comum, concluímos que a cultura surda e a língua de sinais seriam referências do povo surdo" (2015, p. 38). Com isto, compreendemos que o sujeito surdo faz parte de duas culturas com características distintas, mas estas peculiaridades linguísticas e culturais são de grande valia para a formação identitária do sujeito surdo. Na discussão de Figueira,

aprendemos que ser surdo é poder falar com as mãos, mas também aprender uma língua de modalidade oral e auditiva por meio da sua língua materna. É conviver com pessoas tanto do universo do barulho como do universo do silêncio e, essas características não os fazem inferiores, nem superiores, mas diferentes (FIGUEIRA, 2011, p. 44).

Nesta esteira de pensamento, Perlin e Strobel afirmam que, "a educação de surdos fundamentada na diferença e na mediação intercultural entre surdos e ouvintes parece ser o caminho hoje, pois a partir do momento que os surdos são colocados com suas diferenças é que acontecem as trocas" (2008, p. 29). Diante das discussões feitas, compreendemos que a educação das pessoas surdas, quando baseada na diferença cultural entre surdos e ouvintes, contribui para o processo de construção, desconstrução e reconstrução do sujeito por meio da sua cultura, de sua língua e de sua história; isto é, possibilita uma formação muito mais democrática e plural. Para Perlin e Strobel, essa concepção apresenta-se como

[...] uma nova interpretação de caminhos percorridos, para a deferência do povo surdo, dando lugar à sua cultura, valores, hábitos, leis, língua de sinais, bem como à política que movimenta tais questões, e não mais a excessiva valorização da história registrada sob as visões do colonizador, uma história que dá lugar ao sujeito. Ela não interpreta o sujeito como algo fora de contexto, inventado, mas o sujeito como instrumento histórico no sentido e no significado (STROBEL, 2008, p. 21).

Pelo exposto, observamos que o sujeito não pode ser compreendido fora do seu contexto circunstancial, e que a sua identidade e sua cultura são desconstruídas, reconstruídas por meio das experiências e das formas de interpretar e interagir com o mundo. Neste entendimento, as pessoas surdas possuem uma cultura própria e diferente da dos ouvintes. Segundo Strobel a cultura surda é

o jeito de o sujeito surdo entender o mundo e de modificá-lo a fim de tornálo acessível e habitável, ajustando-o com as suas percepções visuais, que contribuem para a definição das identidades surdas e das "almas" das comunidades surdas. Isto significa que abrange a língua, as ideias, as 
http://dx.doi.org/10.5902/1984686X38705

crenças, os costumes e os hábitos do povo surdo (STROBEL, 2008, p. 22, grifos da autora).

Concordamos com a autora, de que ser surdo é possuir um jeito particular de ver o mundo, bem como de utilizar as experiências visuais para tornar o mundo mais próximo de si e dos seus pares, pois entendemos que a cultura surda abarca todas as apreensões de mundo das pessoas surdas e esta se manifesta por meio de artefatos. Estes artefatos são expressos pelas produções linguísticas, artísticas e literárias da comunidade surda. A este respeito, Streiechen esclarece que os artefatos da cultura surda estão "relacionados às experiências visuais, bem como a questão linguística, a literatura surda, à vida social e esportiva, às artes visuais, às lutas e outras tecnologias que facilitem a acessibilidade das pessoas surdas" (2013, p. 111).

Neste contexto, percebemos que os artefatos culturais são muito importantes para assegurar uma educação democrática e plural entre surdos e ouvintes, uma vez que os elementos da cultura surda representam a forma peculiar com que estas pessoas entendem o mundo e expressam seus pensamentos e sentimentos. Dito de outra maneira, os artefatos da cultura surda contribuem para a consolidação das experiências visuais, por meio da língua de sinais. Coaduna com esta afirmação a perspectiva de Perlin e Miranda, ao enfatizarem que a

[...] experiência visual significa utilização da visão, (em substituição da audição) como meio de comunicação. Desta experiência visual surge a cultura surda representada pela língua de sinais, pelo modo de ser, de se expressar, de conhecer o mundo, de entrar nas artes, no conhecimento acadêmico (PERLIN; MIRANDA, 2003, p. 218).

Pelo exposto, a cultura surda é mesclada por artefatos culturais que contribuem para a formação da identidade surda. Vale ressaltar que, entre os vários artefatos presentes na cultura surda, discorremos e analisamos apenas acerca da Língua Brasileira de Sinais (Libras) e a Literatura Surda.

A Libras representa um marco de grande envergadura para a comunidade surda, pois, por meio desta língua de modalidade viso-espacial, a comunidade surda consegue difundir as conquistas e bandeiras de luta do povo surdo. Reconhecida legalmente por meio da Lei de ㄲo 10.436 (BRASIL, 2002) e regulamentada pelo Decreto de o 5626 (BRASIL, 2005) como a língua dos surdos brasileiros, também é um importante artefato cultural para as pessoas surdas. Amparando este entendimento, Streiechen afirma que "a língua de sinais constitui o 'artefato linguístico' das pessoas surdas e é primordial para a 
http://dx.doi.org/10.5902/1984686X38705

cultura surda, hoje reconhecida como primeira língua do povo surdo" (2013, p. 111, grifos do autor).

A Libras, por ser uma língua de modalidade viso-espacial, atende a todas as peculiaridades linguísticas e visuais das pessoas surdas. Assim, configura-se como uma língua que é expressa por sinais, autônoma e possui uma estrutura própria, diferente da língua portuguesa, que é uma língua de modalidade oral auditiva. Com isto, apreendemos que, para que as pessoas surdas possam ter uma educação cidadã, democrática e plural, faz-se necessário que suas peculiaridades linguísticas e culturais sejam respeitadas e valorizadas nos ambientes educacionais. Isto porque muitos ambientes escolares ainda seguem um modelo educacional monocultural, excludente e de silenciamento das pessoas surdas. Esta afirmação vai ao encontro do pensamento de Lopes, ao destacar que

[...] sirenes, disposição das classes em salas de aula, da carência de recursos visuais para auxiliar a aprendizagem do distanciamento tecnológico dos alunos, da "incapacitação" de professores para o uso da LIBRAS, da ausência de professores surdos em sala de aula [...], os sujeitos surdos passam a ser controlados e disciplinados pela escola que, por sua vez, vem se orientando sobre os discursos patologizantes (LOPES, 2005, p. 112).

Frente a esta realidade, bem como da isenção de produções realizadas pela comunidade surda nos ambientes escolares, abordamos a respeito da Literatura Surda. $\mathrm{O}$ ato de contar histórias é importante para despertar a curiosidade, a imaginação, também como forma de resistência, representação ou identificação com os personagens das histórias. Strobel (2015, p. 71) destaca que "os povos surdos transmitem muitas histórias através da língua de sinais; a maioria delas parte das experiências das comunidades surdas, que transmitem seus valores e orgulho da cultura surda, que reforçam os vínculos que unem com as gerações surdas mais jovens". As pessoas surdas, durante muito tempo, não se sentiam representadas nas histórias contadas nas escolas porque todas eram representadas por personagens ouvintes, reforçando o imaginário de que, para serem humanos, inteligentes e bem-sucedidos, careciam ser ouvintes. Entretanto, a fim de desestabilizar essa concepção excludente, monolíngue e monocultural, vários autores começaram e pesquisar e produzir a respeito desse tema. Entre os autores brasileiros que contribuíram para a divulgação da Literatura Surda, destacamos Gladis Perlin (2005); Wilson Miranda (2001) e Karin Strobel (2015), entre outros. 
http://dx.doi.org/10.5902/1984686X38705

Outro fator que merece destaque na Literatura Surda são as traduções, uma vez que várias são as histórias que foram traduzidas para a Libras. Entre as obras traduzidas destacamos "Iracema (José de Alencar, 2002), O velho da horta (Gil Vicente, 2004), O Alienista (Machado de Assis, 2004), O Caso da Vara (Machado de Assis, 2005)" (KARNOPP, 2008, p. 10). Este processo de adaptação de histórias representa uma das formas de os surdos se sentirem representados e respeitados no universo dos ouvintes. Nesta linha de pensamento, Strobel afirma que este "é um processo permanente de respeito do "ser surdo" (2015, p. 70), mudando a visão da história que garante o valor dos direitos culturais para o povo surdo, transformando as relações de poder, desde a vida cotidiana até os espaços mais públicos". Partindo deste entendimento, observamos que este artefato cultural constitui uma importante ferramenta pedagógica para o processo de ensino aprendizagem das pessoas surdas, bem como o contato dos ouvintes com as produções da cultura surda.

Por meio deste artefato cultural, os surdos conseguem expor suas perspectivas, anseios, sentimentos, e suas dificuldades e angústias por meio de experiências visuais. Com Strobel, compreendemos que "a literatura surda se refere às várias experiências pessoais do povo surdo que, muitas vezes, expõem as dificuldades e/ou vitórias das pressões ouvintes, testemunhando também as ações de grandes líderes e militantes surdos, e sobre a valorização de suas identidades surdas" (2015, p. 68).

Diante das discussões arroladas, esperamos ter deixado claro que as pessoas surdas possuem várias traduções e adaptações literárias, e que estas produções precisam estar inseridas nas práticas pedagógicas como forma de contemplar a cultura surda, e para que os alunos ouvintes possam compreender como as pessoas surdas apreendem o mundo, em uma perspectiva diferente das suas. Com base no reconhecimento das peculiaridades da cultura surda, aventamos uma educação entre surdos e ouvintes sob a perspectiva da interculturalidade, que discutimos na próxima seção.

\section{A interculturalidade como possibilidade}

Dito em outro momento, surdos e ouvintes partilham saberes e compõem a cultura brasileira por meio da infusão de perspectivas culturais. Mas vale a observação de que ainda existe um longo caminho a ser trilhado, a fim de assegurar uma educação democrática e plural entre estes grupos. Neste sentido, defendemos que a Educação 
http://dx.doi.org/10.5902/1984686X38705

entre surdos e ouvintes deve ser baseada na interculturalidade. Por interculturalidade apreendemos como uma possibilidade educacional, na qual surdos e ouvintes dialogam, trocam e mediam características e peculiaridades linguísticas e culturais, contribuindo, assim, para a formação de todos de forma democrática. Esta perspectiva tem como ponto de partida a diferença e o combate às desigualdades. Nas palavras de Candau e Koff, esta perspectiva contribui para:

[...] uma dinâmica de crítica e autocrítica, valorizando a interação e comunicação recíprocas entre os diferentes sujeitos e grupos culturais. A interculturalidade orienta os processos que têm por base o reconhecimento do direito a diferença e a luta contra todas as formas de discriminação e desigualdade social. Tenta promover relações dialógicas e igualitárias entre pessoas e grupos que pertencem a universos culturais diferentes, trabalhando os conflitos inerentes a esta realidade (CANDAU; KOFF, 2006, p. 102).

Ao pensarmos em uma educação intercultural entre surdos e ouvintes, compreendemos que o processo de ensino e aprendizagem tem como escopo a incompletude dos saberes, as trocas e os diálogos possíveis entre estes grupos. Isto porque a perspectiva intercultural tenta desestabilizar a ideia da monocultura, da hegemonia do saber e do monolinguíssimo. A este respeito, Dorziat adverte que "desconsiderar essa nova ordem social no contexto educacional significa não estar atento às novas exigências sociais, dificultando, assim, o desvendamento e a superação dos problemas existentes, em direção a uma cultura mais justa e menos excludente" (2009, p. 11).

Com tal afirmação, compreendemos que, ao conjecturar acerca de uma educação que atenda aos princípios da interculturalidade, contribui-se para que as pessoas surdas sejam vistas como cidadãos ativos e capazes de construir a sua própria história, uma história com narrativas, memórias, empoderamento e mediação cultural.

Neste norte, o trabalho aqui proposto intenta possibilitar reflexões acerca da Educação que vem sendo ofertada aos surdos. Isto é, pretendemos fomentar discussões a respeito de uma educação que respeite e valorize as diferenças e peculiaridades históricas, educacionais e linguísticas presentes na cultura surda.

Isto porque advogamos em prol de uma Educação democrática e plural, sob a perspectiva da interculturalidade entre surdos e ouvintes. Nas palavras de Candau, "a perspectiva intercultural quer promover uma educação para o reconhecimento do outro, o diálogo entre os diferentes grupos socioculturais" (2008, p. 10). Ainda segundo a autora, esta possibilidade educacional tem como escopo a construção de uma sociedade mais 
http://dx.doi.org/10.5902/1984686X38705

humana, democrática, plural e que busca igualdade de políticas e de identidade. Com estas argumentações atinamos para a possibilidade de uma educação intercultural entre surdos e ouvintes, que favorece a efetivação da proposta de inclusão em que os alunos surdos são vistos como construtores do conhecimento, juntamente com os alunos ouvintes, por meio do entrelaçamento de saberes e da infusão de perspectivas culturais

\section{Considerações finais}

As buscas históricas, políticas e sociais a respeito da educação das pessoas surdas caminham para a valorização das peculiaridades linguísticas e culturais entre surdos e ouvintes. Com base nesta compreensão, ressaltamos que, por meio das discussões arroladas no corpo do texto e tomando por base uma bibliografia especializada acerca da temática, consideramos que o objetivo aqui proposto foi alcançado, uma vez que proporcionamos várias reflexões sobre a educação que vem sendo proporcionada às pessoas surdas nos espaços educacionais. Como forma de elucidar tais reflexões apresentamos, no primeiro momento, algumas considerações acerca da educação das pessoas surdas e do processo de exclusão cultural e linguístico que os alunos surdos passaram e ainda experimentam, em certa medida, nos dias atuais.

$\mathrm{Na}$ sequência, por defendermos uma proposta educacional baseada na interculturalidade, apresentamos o conceito de cultura no seu sentido lato para que, de posse deste conceito, delineássemos acerca da cultura surda, em que apresentamos as características e os artefatos desta cultura, principalmente, da Libras e da Literatura Surda. Ainda que não tenhamos discutido a política como artefato cultural, de forma mais sistematizada atinamos que ela é um elemento capital no processo de democratização do ensino para o surdo, pois, por meio dela, artefato cultural política, lutas foram organizadas e travadas no sentido de visualizar a cultura surda.

Por fim, ao apresentarmos a importância da cultura surda para formação dos sujeitos surdos, discorremos acerca da interculturalidade como possibilidade de uma educação mais democrática e plural entre surdos e ouvintes.

Como resultados alcançados, podemos elencar que, mesmo diante dos avanços alcançados pelas comunidades surdas nos âmbitos legal, social e educacional, ainda existe um fosso entre a teoria e a prática. Dito de outra maneira, as pessoas surdas ainda são, em certa medida, excluídas nos espaços escolares. Como exemplo dessas práticas, destacamos a falta de conhecimento da Libras nesses espaços, a escassez de obras 
traduzidas e adaptadas em Libras nas salas, a disposição das salas em fileiras, a ausência de intérpretes, entre outros. Frente a esta realidade, acastelamos uma educação intercultural entre surdos e ouvintes, uma vez que esta perspectiva educacional possibilita diálogos e trocas linguísticas e culturais entre estes dois grupos.

Para tanto, diante das ponderações, concluímos que este estudo se configura relevante, pois possibilita ponderações acerca da proposta de educação disponibilizada às pessoas surdas, destacando alguns entraves e, como possibilidade para uma formação democrática e plural, aventamos a educação intercultural. Neste sentido, cabe considerar que estudos futuros podem, inclusive a partir deste trabalho, pautar o artefato cultural política como objeto de pesquisa, uma vez que autores como Bourdieu podem subsidiar a investigação, sobretudo pensando política como instrumento de poder. Também, a realização de estudos empíricos, pois a pesquisa aqui apresentada é bibliográfica, apenas, e existindo um trabalho de campo, certamente outras questões serão apresentadas no que compreende o universo do surdo.

\section{Referências}

BOURDIEU, Pierre. Escritos de educação. São Paulo: Vozes, 2014.

BRASIL. Lei no 10.436, de 24/04/2002. Dispõe sobre a Língua Brasileira de Sinais Libras e dá outras providências.

BRASIL. Decreto no 5.626, de 22/12/2005. Regulamenta a Lei no 10.436, de 24 de abril de 2002, que dispõe sobre a Língua Brasileira de Sinais - Libras, e o art. 18 da Lei $\mathrm{n}^{\circ} 10.098$, de 19 de dezembro de 2000.

CANDAU, Vera Maria; KOFF, Adélia Maria Nehme Simão e. Conversas com... Sobre a didática e a perspectiva multi/intercultural. Educação e Sociedade. RJ: Vozes, 2006 v.27, n.95.

CANDAU, Vera Maria. Multiculturalismo e educação: desafios para a prática pedagógica. In: MOREIRA, Antonio. Flávio; CANDAU, Vera. Maria. Multiculturalismo: diferenças culturais e práticas pedagógicas. Petrópolis: Vozes, 2013.

DORZIAT, Ana; O outro da educação: pensando a surdez com base nos temas Identidade/Diferença, Currículo e Inclusão. Petrópolis, RJ: Vozes, 2009.

FIGUEIRA, Alexandre. Dos Santos. Material de apoio para o aprendizado de Libras. São Paulo: Phorte, 2011.

KARNOPP, Lodenir Becker. Literatura Surda. ETD - Educação Temática Digital, Campinas, v.7, n.2, p.98-109, jun. 2008. 
LOPES, Maura. Corcini. Relações de poderes no espaço multicultural da escola de surdos In: SKLIAR, Carlos. (Org.). A surdez: um olhar sobre as diferenças. Porto Alegre:

Mediação, 2005.

LULKIN, Sérgio. Andrés. O discurso moderno na educação dos surdos: práticas de controle do corpo e a expressão cultural amordaçada. In: SKLIAR, Carlos. (Org.). A surdez: um olhar sobre as diferenças. Porto Alegre: Mediação, 2005.

OLIVEIRA, Liliane Assumpção. Fundamentos Históricos, Biológicos e Legais da Surdez. Curitiba: IESD Brasil S.A., 2011.

PERLIN, G e MIRANDA, W. Surdos: o Narrar e a Política In Estudos Surdos - Ponto de Vista: Revista de Educação e Processos Inclusivos nํ5, UFSC/ NUP/CED, Florianópolis, 2003.

PERLIN, Gladis. Identidades surdas. In: SKLIAR, Carlos. (Org.). A surdez: um olhar sobre as diferenças. Porto Alegre: Mediação, 2005.

PERLIN, Gladis e STOEBEL, Karin. Fundamentos da Educação de Surdos. Florianópolis: Editora da UFSC, 2008

SANTANA, Ana Paula. Surdez e Linguagem: aspectos e implicações neolinguísticas. São Paulo: Plexus, 2007.

SANTOS, Adriana Padro Santana; GOES, Ricardo Schers de. Língua Brasileira de Sinais. Indaial - SC: Uniasselvi, 2016.

STREIECHEN, Eliziane. Manosso. LIBRAS: aprender está em suas mãos. Curitiba: CRV, 2013.

STROBEL, Karin. Surdos: vestígios culturais não registrados na história. Florianópolis: UFSC, 2008.

STROBEL, Karin. História da Educação de Surdos. Florianópolis: UFSC, 2009.

STROBEL, Karin. As imagens do outro sobre a cultura surda. Florianópolis: Ed. da UFSC, 2015.

WEBER, Max. Ciência e Política. Duas vocações. São Paulo: Cultrix, 1968.

\section{Notas finais}

\footnotetext{
${ }^{1}$ Este e termo é utilizado por Lulkin (2005) para demostrar que existia um fosso e uma ideia de norma entre a as pessoas surdas e ouvintes, isto é, que as pessoas eram vistas como normais a partir das habilidades do ouvir e do falar. Com isto, as pessoas surdas que apresentavam perda parcial ou total no ouvir dessas habilidades eram classificadas como uma pessoa uma perda, uma carência, uma falta, uma deficiência. Essa nomenclatura demarca e reforça a ideia de inferioridade e aprisionamento das pessoas surdas por sua condição fisiológica.
} 
2 Para Bourdieu (2012), por campo estende-se a arena política, o lugar da disputa. No capítulo III de O poder Simbólico, denominado de a gênese do conceito de habitus e de campo, o autor faz um estudo do conceito e acrescenta, justamente, a definição de um lugar específico, um lugar de disputa.

${ }^{3}$ Para Moura (2007), o dia do surdo tem um sentido muito importante para o povo surdo, pois representa o conhecimento de todo um movimento de luta, que é muito recente no país. Esta luta resultou no reconhecimento de que o povo surdo possui língua e cultura próprias.

${ }^{4}$ No estudo da Filosofia, mais precisamente na história da Filosofia, autores como Geovane Reale e Julían Marías estão de acordo que, no mundo antigo, o grego e o romano, havia um sentimento do belo, isto é, uma discussão estética em torno do mundo e do corpo, ou seja, a estética era o filtro do mundo (REALE, 2006).

${ }^{5}$ Karnopp (2001, p. 173) cita o relato de uma universitária surda: Eu não conhecia muitas palavras de português. Eu escrevia e as pessoas não entendiam o que eu escrevia; eu aprendia sozinha. As vezes os professores faziam ditado oral; era horrível; ficava envergonhada; meu irmão, em casa, me ensinava claramente português. A professora não era clara. Os alunos não compreendiam o texto, a leitura; [...] faltou livros no colégio; eu não acostumei na Universidade, fico confusa e nervosa. Tenho vergonha que as pessoas não entendem as frases que escrevo.

${ }^{6}$ Bourdieu (2014), no texto Escritos de educação, faz um diagnóstico da escola francesa e apresenta que, nos anos 60 , as pessoas acreditavam que adentro na escola, automaticamente, descontava-se um horizonte social melhorado. Isto porque, segundo ele havia, no discurso da escola libertadora, uma possibilidade, mas do que isto, uma garantia. Todavia, ainda segundo este autor, constatou-se que o discurso era uma maneira de conservar uma ordem social. Nas palavras de Bourdieu (2014, p. 246), "com efeito, depois de um período de ilusão e mesmo de euforia, os novos beneficiários compreenderam, pouco a pouco, que não bastava ter acesso ao ensino secundário para ter êxito nele, ou ter êxito no ensino secundário para ter acesso às posições sociais que podiam ser alcançadas com os certificados escolares e, em particular, o bacalauréat, em outros tempos, ou seja, nos tempos em que seus pares sociais não frequentavam o ensino secundário". É certo que, no entendimento de Bourdieu, não basta frequentar a escola, é preciso modificar as estruturas da escola.

\section{Correspondência}

Valikiria de Novais Santiago - Universidade Estadual do Paraná, Rua Coronel Amazonas, Centro, União da Vitória, Paraná - Brasil.

CEP: $84600-000$.

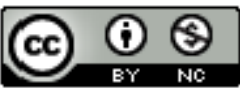

This work is licensed under a Creative Commons Attribution-NonCommercial 4.0 International (CC BY-NC 4.0)

\section{Modalidade do artigo: Relato de pesquisa ( ) Revisão de Literatura ( X)}

